\title{
¿ES ESTO UNA OBRA DE ARTE? LA REALIZACIÓN ARTÍSTICA DE UNA IDEA ESTÉTICA KANTIANA POR UN DESCONOCIDO MR. MUTT.
}

\author{
Simón MARCHÁN FIZ \\ UNED
}

\begin{abstract}
«Un juicio de gusto, en lo que se refiere a un objeto de fin interno determinado, sería puro sólo cuanto el que juzga no tiene concepto alguno de ese fin o hiciera en su juicio abstracción de él»
\end{abstract}

(Kant, Critica del Juicio, $\$ 16$ ).

En el proceso de diferenciación que acompaña a la constitución del sujeto moderno, la estética desborda la distante reflexión sobre la relación o el juicio estéticos para implicarse en la legitimación del nuevo estatuto alcanzado por el arte. En su confluencia, la autonomía de éste y la de aquella nueva disciplina ilustrada son correlativas, ya que a medida que el arte se desliga de sus funciones heterónomas, se afianza como arte absoluto, mientras la estética, escorada pronto hacia una filosofía del arte, parece concederle el monopolio de lo estético y privilegiar su espacio público.

Desde semejante óptica, si bien no todo lo estético es artístico, sí todo lo artístico es estético, siendo la obra de arte su cristalización más depurada, y la diferencia o función estética, en cualquiera de sus interpretaciones, el rasgo distintivo que lo separa de otras objetivaciones humanas. No me sorprende por tanto que cuando ciertas experiencias artísticas cuestionen el estatuto de la obra de arte autónomo, sobrevengan las tribulaciones de la diferencia estética. En concreto, en las vertientes del llamado arte objetual, que transfigura objetos de la vida cotidiana en obras artísticas, la categoría de arte se estira tanto, que amenaza con romperse en su comprensión; o si se prefiere su definición extensiva rebasa de tal manera a la intensiva, que torna problemáticas las diferencias entre 
lo que se acostumbra a considerar como una obra de arte y los objetos cotidianos que nos envuelven.

Los trazos a primera vista desvanecidos de la diferencia estética despistan tanto a ese público generalista, presto a lanzar la embarazosa pregunta sobre su esto o lo de más allá es arte, si es que no la más metafísica: ¿qué es el arte?, como a quienes todavía exhiben definiciones esencialistas o, o al menos, universalistas. No le faltaba pues razón a Th. Adorno cuando, tras su inmersión en la experiencia artística moderna, nos alertaba desde la primera línea de su Teoría estética sobre la circunstancia de que ha llegado a ser evidente que nada referente al arte es evidente. Providencia que en pocas ocasiones estaría tan certeramente traída a colación como ante una obra que suscitó un amplio debate en su momento y lo continúa provocando en la estética actual, ya que es premonitoria y paradigma de todas aquellas que desde entonces han vuelto a disparar el interrogante: ¿Es esto una obra de arte?

Me refiero, como muchos pueden imaginar, a la Fuente, un objeto industrial fabricado en serie, que es transfigurado sin transformación física alguna en una obra de arte. Tal vez no sea exagerado sostener que la actualidad de la Fuente en la estética más reciente, sobre todo en la norteamericana, sólo es comparable a la de las tesis de W. Benjamin sobre la situación del arte en la época de la reproductibilidad técnica. Por mi parte, la tomaré como un banco de pruebas para explorar la convicción adorniana o derridiana de que la configuración de la estética actual es la disolución o deconstrucción de las categorías al uso.

\section{El caso de Richard Mutt ante la institución arte}

Desde la estética de la recepción, la obra artística se ha visto envuelta en ciertos procesos similares a los de una vista judicial, cuya resolución reenvía a juicios axiológicos. Emitidos por un tribunal de especialistas o por un público innominado, se almacenan en la memoria colectiva, sancionando obras y creando precedentes para casos semejantes. Diríase, pues, que sientan una cierta jurisprudencia crítica o espontánea de la que brotarán unas legitimaciones teóricas que, aunque no se impongan con fuerza alguna de ley, generan consensos y, por ende, nuevas convenciones. Esto se desprende al menos de los sucesivos escándalos que han jalonado la historia artística moderna. En la superficie están provocados por una transgresión de las convenciones precedentes, 
pero en el fondo, en ellos late un conflicto de interpretaciones que suele manifestarse airadamente en un aserto casi normativo: "Esto no es una obra de arte».

Podríamos aducir ejemplos tan sonados como la Olimpia de Manet, la Edad de bronce de Rodin, las Señoritas de Aviñón o El pájaro en el espacio de Brancusi, el cual desató incluso un proceso judicial en la aduana neoyorquina, pero, sin duda, el levantado por la Fuente ha sido el más provocativo y preñado de secuelas teóricas hasta nuestros dias. Conocido como el "Caso de $R$. Mutt), suscitó un litigio que, si bien no se sustanció, como el de Brancusi, ante una corte de justicia, si se dilucidó ante un jurado que actuaba en nombre de la institución de arte autónomo.

En efecto, de acuerdo con el programa de la Sociedad de Artistas Independientes, creada en Nueva York en diciembre de 1916, cualquier persona podía convertirse en uno de sus miembros y, por consiguiente, en artista, si aceptaba sus principios: "Ni jurado ni premios" y pagaba la cuota de inscripción. Ello le garantizaba por lo demás que cualquier cosa que enviara sería colgada en sus salas. Cuando en abril del año siguiente se abrió al público en su primera exposición, fueron mostradas cerca de dos mil quinientas obras de unos mil doscientos proclamados artistas. Sin embargo, contraviniendo unos criterios tan elásticos, el comité organizador vetó una obra titulada Fuente: un urinario masculino de porcelana blanca, probablemente un Bedforshire plano por detrás y con labio, que estaba fechado y firmado en uno de sus bordes por un artista hasta entonces desconocido: R. Mutt.

La Fuente no fue vista por el público, ni incorporada al catálogo de la exposición, por lo que en su día solamente se dió a conocer a través de una fotografia tomada «in situ" y apenas se supo nada sobre ella hasta los años cincuenta y sesenta cuando su verdadero autor ofreció varias réplicas de la misma. Por su parte, el citado comité, constituído por los más respetables miembros de la vanguardia, se limitó a informar de su exclusión con esta escueta nota: "La Fuente puede ser un objeto muy útil en su sitio, pero su sitio no es el de una exposición de arte, y, por definición, no es una obra de arte» ${ }^{1}$. Una vez más, la exclusión traslucía un conflicto de interpretaciones sobre los criterios diferenciadores.

1 Citado por W. CAMFIELD: M. Duchamp Fountain, Houston, The Menil Collection, Fine Art Press, 1989, pág. 27; de no señalar otra procedencia, los sucesivos testimonios están tomados de esta monografia. 
En desacuerdo con esta decisión, uno de los organizadores de la muestra, M. Duchamp, no sólo dimitió del comité en supuesta solidaridad con aquél artista rechazado, sino que promovió la fundación de la revista The Blind Man, en la que aparecia una fotografía de la obra vetada, así como el editorial anónimo: El caso de Richard Mutt, en donde se rebatían los argumentos morales y artísticos de la exclusión. Lo más chocante sin embargo fue que A. Stieglitz, el fotógrafo vanguardista más de moda, no estaba al corriente, como casi nadie, de quien era su verdadero autor. La sorpresa fue mayúscula cuando el propio Duchamp puso sus cartas al descubierto. Unas cartas con las que, aunque nadie reparaba en ellas, venía jugando desde que poco antes mostrara sin pena ni gloria en dos galerías de la misma ciudad algunos objetos tan cotidianos como una Rueda de bicicleta, un Portabotellas o una Pala quitanieves, a los que denominaba Ready-mades.

En el debate suscitado por la Fuente entre los miembros del comité organizador, la mayoría la consideraron una broma, cuando no una provocación, mientras que para una minoría se trataba de un test. Pero si Duchamp, a pesar de ciertas negaciones tardías, se decidió a enviarla, era sin duda porque confiaba en que fuera aceptada como una obra de arte, mientras para los organizadores se encontraba entre las candidatas que debían satisfacer los criterios para ser reconocidas en tal condición. No obstante, su exclusión no trasluce sino que, como comentaba irónicamente una crítica anónima en The New York Herald (14/04/1917) «su arte es demasiado crudo para los Independientes». Por ello no había superado la prueba, pero importaba poco, ya que no tardaría en pasarla en virtud de la apariencia alegórica que proporcionaba la fotografía.

Sea como fuere, su transformación en una obra de arte no era sino el fruto de una complicidad en doble dirección: un autoproclamado artista, tras decidir que algo es arte, lo envía a una exposición en la confianza de que, al ser aceptado en ella, se legitima tanto el objeto en cuestión en su condición artística cuanto su autor como artista. Esto era al menos lo que se desprendía del programa, ahora incumplido, por parte de la Sociedad de Artistas Independientes.

No me parece fortuito en esta tesitura que, sobre todoen la estética norteamericana reciente, la Fuente y los restantes Ready-mades, situados en el polo extremo de un arco artístico muy tensado, hayan sido considerados muy valiosos para la llamada "teoría institucional del arte» como candidatos a una 
apreciación estética por unas personas o grupos que, autonombrados conservadores de un virtual museo imaginario, actúan en función vicaria de la institución Arte. Desde esta presunción, que no disimula la ambición de postular una definición universalista del arte, las obras serían artísticas a resultas de la posición que ocupan en "el mundo del arte», que es el llamado a otorgarles semejante estatuto. Más en concreto, la circunstancia de que la Fuente sea apreciada como una obra de arte y otro urinario, aun cuando presente rasgos visuales similares, no lo sea, exige que la primera "debe estar enredada en algún tipo de marco (framework) o red de relaciones en las que el segundo elemento no lo estám 2 .

$\mathrm{Si}$ bien es plausible que la teoría institucional constate en abstracto una legitimación primeriza, creo que, precisamente, deja en la penumbra esa tupida red de relaciones en la cual un objeto cualquiera quedaria atrapado como una obra de arte. Aunque la supone, no explicita sin embargo la particularidad artística de la Fuente respecto a otros urinarios de su mismo sistema objetual. Como aconteciera en la Sociedad neoyorquina, no parece sustraerse a una circularidad, ya que no matiza las diferencias entre el objeto de una serie que ha triunfado como candidato a una apreciación artística, que ha pasado la prueba institucional, y el que no la ha superado. Es cierto que supone un pacto de convenciones técnico-estéticas, así como la premura por renegociar otras, pero apenas fija los criterios implícitos en unas o en otras.

Coincidiendo con el redescubrimiento de Duchamp, J. Kosuth propugnó durante los años sesenta, que después de los Ready-mades, la obra de arte «es una especie de proposición presentada dentro del contexto del arte como comentario artístico", así como que "el artista nos está diciendo que aquella obra concreta de arte es arte" ${ }^{3}$. Este fue el punto de partida del "conceptualismo lingüístico", hoy en día superado por el propio artista, que, inspirándose en las proposiciones analíticas del neopositivismo lógico, renegaba del pensamiento trascendental mundano desde Kant hasta Husserl o Meleau-Ponty y defendía una separación radical entre la percepción y el concepto, entre la estética y el

2 G. DickIE: «The New Institutional Theory of Art» (1984), en DickIE y otros: Aesthetics: an Anthology, Nueva York, St. Martin Press, 1989, pág. 200; Cfr. págs. 196-205, 214-17; idem: Art and Aesthetics: An Institutional Theory, Ithaca, Nueva York, Cornell Univ., 1974, págs. 34 ss.; P. Bürger: Teoría de la vanguardia (1974, Barcelona, Península, 1987, págs. 106-107).

3 J. KosUTH: "Arte y filosofía” (1968), en G. BATTCOCK ed.: La idea como arte, Barcelona, G. Gili, 1977 , págs. 80 y 61 ; Cfr. págs. 68 ss. 
arte, en beneficio de un intencionalismo solipsista y la tautología a la manera de Wittgenstein. Retornaré sobre esta escisión entre la estética y el arte.

Esta teoría contextual, variante matizada de la institucional, es el telón de fondo tras el cual se alza también una versión actualizada y exitosa de la Estética Analítica, la de A. Danto. Al igual que en Dickie, el desencadenante de la reflexión es cómo definir el arte después de Duchamp, Warhol o el Conceptualismo de Kosuth. Incluso, asumiendo la tesis más radical del último: todo el arte es conceptual, toma como excusa a la Fuente y los restantes Ready-mades para tratar de verificar que las cualidades perceptivas o propiedades estéticas no pueden determinar de un modo adecuado a la obra de arte, ya que entre dos objetos similares de una serie: urinario, rueda de bicicleta o pala quitanieves, no estamos en condiciones de diferenciar el que se ha transfigurado en una obra artística o el que permanece siendo uno cotidiano. Como en Kosuth, los Ready-mades evidencian el fracaso de la Estética. La transfiguración artística de lo banal no parece depender por tanto de sus propiedades perceptivas en nada distintas a las de los restantes objetos de la serie, sino de un acto de interpretación, que no ha de entenderse desde la práctica hermenéutica, sino en cuanto función que transforma un objeto cotidiano cualquiera en una obra artística, confiriéndole así una identidad segregada:

«Decir de aquel urinario, matiza Danto, que es una Fuente es en efecto un caso de lo que en otro lugar he calificado una identificación artística, en donde el "es" en cuestión es concordante (.....) con la falsedad literal de la identificación" " , con la fuente, que ha suplantado al urinario. La interpretación se torna pues una operación constituyente en la conciencia estética, ya que ningún objeto es transfigurado en obra de arte con anterioridad a este acto: el de la identificación artística, tal como la reconocemos a través de la cópula «es». Una cópula que se pronuncia en la atmósfera de una teoría artística y de un saber referido a la propia historia del arte, al mundo artístico; o, añadiría, a la autoconciencia moderna del arte como medio de reflexión desde el romanticismo temprano y el "después del arte» hegeliano con el que sintoniza Danto.

Tanto Kosuth, mediante la proposición analítica, como Danto, a través de la interpretación, cuando declaran: «Esto es una obra de arte» participan de

4 A. Danto: The philosophical Disenfranchissement of Art, Columbia University Press, 1986, pág. 41; Cfr. págs. 23 ss.; idem: The Transfiguration of the Commonplace, Harvard University Press, 1981, sobre todo Cap. 4 y 5. 
una ceremonia nominalista en la que confluyen la teoría institucional y la contextual hasta casi fusionarse. Incluso resulta paradójico, teniendo en mente los desarrollos artísticos después de Duchamp, que ambas recaigan en una definición universalista del arte. Desde sus posiciones, cualquier objeto es candidato a ser transfigurado en una obra artística siempre y cuando sea sancionado en tal condición por la institución arte que lo identifica a través de una teoría artística en su correspondiente marco o contexto. Dejando a un lado que da la impresión de que la identificación se subordina a la teoría, al borrar las huellas perceptivas del objeto en aras de la esencia conceptual o filosófica, otorgan un protagonismo abusivo a una interpretación que coincide al máximo con las intenciones del artista. Derivan así a un intencionalismo que ha sido devaluado a menudo por Duchamp al equiparar al espectador y al creador, al que mira o al que hace o elige el objeto. Un intencionalismo que impregna hasta hoy en día las sesiones críticas de las Escuelas de Arte norteamericanas.

Desde otro ángulo, la apelación a estas instancias roza de contínuo la tautología o la circularidad, pues desde el momento en que se recluye en un contexto proposicional o teórico, se rompen los vínculos con los estados de cosas, con ciertas condiciones de existencia, con las propiedades singulares de las apariencias, de un étant donné, del que no reniega Duchamp. Aventuro por consiguiente que cuando desde cualquiera de las instancias se identifica a la Fuente o a otros objetos con la declaración: "Esto es una obra de arte", su marco más pertinente no es el paradigma linguiístico del estructuralismo (significante/significado, lengua/habla, etc.), ni el lógico del conceptualismo tautológico (las proposiciones analíticas) o el pragmático (la performatividad del lenguaje), sino, probablemente, el de la función enunciativa.

En esta dirección, parafraseando a M. Foucault, el correlato del enunciado: "Esto es una obra de arte", tiene que ver con un conjunto de dominios en los que pueden aparecer ciertos objetos transfigurados, con unas condiciones de posibilidad o reglas de existencia para los objetos que en él se encuentran, con el campo de emergencia y la instancia de diferenciación de los objetos y las relaciones puestas en juego por el enunciado mismo.

Tal vez por ello, su descripción no puede llevarse a cabo exclusivamente mediante una investigación semántica de las proposiciones analíticas, como propone Kosuth, ni por una verificación de una proposición sintética, sino "por el análisis de las relaciones entre el enunciado y los espacios de diferenciación 
en los que hace él mismo aparecer las diferencias" 5 . Creo que, en este sentido, "Esto es una obra de arte", una vez pasada la prueba, se oferta como un enunciado ostensivo que reenvía a las condiciones bajo las cuales se manifiesta la obra de arte, que no son otras sino aquellos espacios o intersticios que permiten aflorar a las diferencias estéticas respecto a los objetos cotidianos.

La «des-artización» desde la experiencia estética

En una fotografía tomada en 1917 la rueda de bicicleta sujeta por la orquilla invertida y apoyada sobre un taburete aparece en el estudio al lado de los enseres domésticos como un figurante más del interior bohemio. Años más tarde Duchamp insistirá en que no tenía una idea preconcebida sobre ella, ni intenciones de exponerla, ya que se trataba de una mera "distracción" ligada al azar en conserva. Asimismo recordará que, cuando empieza a denominar Ready-mades, inspirándose en los conocidos ready-made garmets (prendas de vestir confeccionadas), a este objeto y a otros no menos inespecíficos, "parecían adecuarse perfectamente a cosas que no eran obras de arte..., que no se aplicaban a ninguna de las expresiones aceptadas en el mundo artístico» ${ }^{6}$.

Desde luego, si en el momento de enviar la Fuente hubiera pensado así, no hubiera tenido argumentos para oponerse a su exclusión, lo cual me sugiere que tanto la adecuación como la aceptación pendían de los tenues filamentos de unas convenciones a punto de ser revocadas. Su airada reacción se comprende únicamente desde la óptica de semejante revocación, es decir, desde la urgencia por justificar los criterios estéticos bajo los cuales ese objeto inespecífico aspiraba a ser juzgado como una obra de arte y a no ser confundido con otro urinario de su misma serie. Por otro lado, a pesar de sus declaraciones ambivalentes o contradictorias durante los años sesenta, nunca se sintió satisfecho con sus propias definiciones del Ready-made, en más de una ocasión reconocería su fracaso en su intento de no hacer arte, ya que se alegraba de ser un artista. Por ello, antes de proseguir, creo que vale la pena transcribir los criterios que le animaron a

5 M. FouCAuLT: La arqueología del saber, México, Siglo XXI, 1979, 7.a ed., pág. 153; Cfr. pág. 147 ss. Esta es la perspectiva adoptada recientemente por Thierry DE DuVE: Kant after Duchamp, Cambridge Mass. The MIT Press, 1996, pág. 382 ss.

6 P. Cabanne: Conversaciones con M. Duchamp (1967), Barcelona, Ed. Anagrama, pág. 71. Se citará como Cabanne. 
dimitir del comité organizador y lanzar esa suerte de manifiesto en que se convirtió el editorial anónimo en The Blind Man (n. ${ }^{\circ} 2$, mayo, 1917):

«He aquí los motivos para rechazar la Fuente del sr. Mutt. 1.-Algunos arguyeron que era inmoral, vulgar. 2.-Otros, que era un plagio, una simple pieza de fontanería. Ahora bien, la Fuente del sr. Mutt no es inmoral, esto es absurdo, no es más inmoral que una bañera. Es un accesorio que se ve cada día en los escaparates de los fontaneros. Si el sr. Mutt hizo o no hizo la Fuente con sus propias manos, no tiene importancia. Él lo ELIGIÓ. Cogió un artículo ordinario de la vida y lo colocó de tal modo, que su significado útil desapareció bajo el nuevo título y punto de vista: creó un nuevo pensamiento para aquel objeto. En cuanto a la fontanería no es absurdo. Las únicas obras de arte que ha dado América son la fontanería y los puentes».

Dejaré de lado las razones morales rebatidas, comunes por lo demás a los habituales escándalos artísticos, pues no atañen al nudo del asunto: la declaración de la Fuente o de otro objeto útil en obra de arte. Me importa, en cambio, resaltar que, con la Fuente se inicia una pérdida del origen respecto a lo que en el mundo artístico o en el orden metafísico se entendía por la identidad tradicional o moderna de la obra artística en aras del proceso de transfiguración. Fruto de un gesto arbitrario o de la provocación, la irrelevancia de si la ha hecho o no con sus manos denota que el acto creativo, la Poiesis, ya no es deudor, como era lo habitual, de la techné, de un hacer asociado con las habilidades de la mano, con el dominio de un oficio y una técnica que transforma una materia, pues no hay materia ni forma en la acepción tradicionales. El Ready-made, en cuanto ya hecho, permitía así reducir «la idea de la consideración estética», como confesará a los Janis en $1953^{7}$, a la elección de la mente, y no a la habilidad y destreza de la mano, algo que tanto le molestaba en los pintores de su generación. No existe un artifex facit, sino una elección, aunque, tal vez, le cuadraría mejor un término más reciente: intervención, pues implica por igual a la mera elección y a la acción o actuación sobre los objetos. Una acción que se torna más rastreable en los Ready-made aided o assisted, es decir, en los que incide con una manipulación que los puede modificar parcialmente.

Al reaccionar contra las acusaciones de plagio, Duchamp se defendía de quienes le criticaban su falta de originalidad - una categoría central en la

7 Cfr. M. Duchamp, Nueva York, MOMA, 1973, pág. 275. 
estética del genio-, aunque, sin embargo, reconocían a veces que los Readymades, vistos en conjunto, no dejaban de ser originales en su trato con los objetos. Asimismo, el hecho de que a las réplicas posteriores les conceda el mismo valor que al «original" sugiere que ya no obedecen a la lógica categorial de la obra única y que sintonizan con la inexistencia de diferencias entre el original y la copia, con una estética de la reproductibilidad. Sin embargo, aquí se delata otra de sus paradojas artísticas, ya que en las réplicas de la Fuente, como la que realiza en 1950, intentaba que, en lo posible, tuviera la misma forma, dimensión y colocación que el original, y en las posteriores se implicó en la reproducción exacta. Incluso, en una edición de diez ejemplares especificaba el tamaño, el precio y las condiciones de presentación según unos planos firmados y aprobados antes de ser reproducidas, basados en fotografias antiguas, lo cual traslucía una voluntad de recuperar el original.

Considerados como una supuesta expresión, los Ready-mades se anticipan a la crisis o muerte del autor, de quien únicamente conservan rasgos residuales como el fetichismo de la firma. Claro, que la firma atestigua la invención del sujeto moderno. Aun reconociendo esta condición, Mutt no es sino una tomadura de pelo respecto a su persona y una broma que altera la empresa fabricante de los urinarios, la Mott Iron Works, en beneficio de un protagonista muy popular de un tebeo humorístico. Así pues, en vez de traslucir la hechura, lo subjetivo a través del toque de la pincelada o la factura pictórica, el nombre del autor sólo se reconoce en las huellas que deja, pero, al ocultarse como Mutt o travestirse como Rrose Sélavy y otros, elude la responsabilidad ante lo ya hecho, lo ready-made, renuente a desplegar la autoridad de un creador que se ha convertido en mero transformador.

Protegido bajo sucesivos pseudónimos, en uno de ellos es incluso «Wanted» como un forajido del Oeste por "2.000 dólares de recompensa". Paradójicamente, cuando se le encontró años después, alimentaba, como sucede en las películas, la más fascinante leyenda artística del siglo XX. Iconoclasta frente a la convención, tal vez la ironía e irresponsabilidad más provocativas se consuman cuando nos invita a "Comprar o coger cuadros/conocidos o desconocidos/y firmarlos con el nombre de un/pintor conocido o desconocido - La diferencia entre la "factura" y el nombre inesperado para/los "expertos"-, es la obra auténtica de Rrose Sélavy/y resiste/las falsificaciones»" ${ }^{8}$.

8 M. Duchamp: Notas, Madrid, Tecnos, 1989, n.o 169, pág. 147: "Introducción de G. Moure", págs. 9-16; Las citaré entre paréntesis; M. DuCHAMP: "El proceso creativo» en 
Las huellas del autor «buscado» se imprimen también de un modo difuso en «inscribir a un ready-made», en la inscripción escritural, con tal fecha, hora, minuto, tomados cual informaciones o una suerte de "cita" para después dar con él sin agobios. No obstante, lo más frecuente es que la inscripción, en vez de describirlo como haría un título, sea una frase que, como la de Pala quitanieves. "en adelante del brazo de M. Duchamp", estaba destinada a transportar la mente del espectador hacia unas regiones más verbales. Los encantos de Mallarmé y de R. Roussel eran irresistibles, mientras en las letras del francés o del inglés desprendidas en ¿Por qué no estornuda Rrose Sélavy? bromea sobre su alter ego femenino ficticio, travestido, encumbrado en la categoría de su propio Ready-made personal.

Al enviar un objeto ordinario de la vida a una exposición se tramnsgredían las convenciones aceptadas por el Salón en nombre de la institución arte. Sobre todo, a sabiendas de que el mundo del arte y el público identificaban la obra de arte con los géneros tradicionales: la pintura y la escultura. Sin embargo, aquellos inespecíficos Ready-mades eran encomiados en ese mundo. Incluso Duchamp, con el fin de soslayar el término "cuadro de vídrio", una convención moderna asumida, denomina, en una evocación más poética que pictórica, a su conocida obra La novia puesta al desnudo por sus subalternos como un "Retrato de vídrio" o una mezcla de acontecimientos que son excrecencia del cuadro en general. Y tensado más el contexto artístico, insinúa que «el hecho de llevar el pantalón/el llevar/el pantalón es comparable a la ejecución/manual de una escultura original" o propone "hacer grandes esculturas uno de cuyos/centros será el escuchador. - Por ejemplo/una inmensa Venús de Milo hecha de sonidos/alrededor del escuchador" (Notas, n. 044 y 83).

A pesar de tales tensiones, la Fuente simulaba ajustarse a las convenciones, si es que todavía le creemos cuando escribe a su hermana (11/04/1917) que una de sus amigas bajo el pseudónimo de Mutt - puro engaño- «envió un urinario de porcelana como una escultura", mientras el año anterior (15/01/1916) aludía a la Rueda de la Bicicleta y el Portabotellas como «esculturas ya hechas" y, en cuanto tales, serían consideradas por algunos de sus admiradores. Aventuro que cual "pequeña maldad" podríamos pensarlas, al igual que una Botella de Bénédictine, como «una concesión irónica/a naturalezas

Duchamp du Signe, Barcelona, G. Gili, 1978, págs. 162-163; J. L. BREA: «Releyendo el acto creativo", en Nuevas estrategias alegóricas, Madrid, Tecnos, 1991, págs. 17-31. 
muertas" (Notas, n. ${ }^{\circ}$ 107). Aunque mirándolo bien, de concesión irónica, nada. No les falta razón en efecto, a quienes denunciaban que la Fuente era vulgar, ya que el urinario elegido era de los de menos prestigio en la escala social; un modelo barato, ligero y fácil de instalar, pero, sin cisterna de agua resultaba maloliente y difícil de limpiar. Solamente los de las prisiones, de latón y sin labio, eran de inferior calidad.

Ahora bien, ¿no eran precisamente los objetos de carácter vulgar, a cuyos contenidos no cabía acercarse con la presunción del cortesano o los refinamientos de la buena sociedad, los que habian sido tomados como materiales del arte desde la pintura de género o las naturalezas muertas entre los holandeses? 9 ¿Eso si!, Duchamp abandona las convenciones ilusionistas del género, las saca de la actualidad de su propia vida y las desvía de una lógica de la representación en aras de la ostensión. En todo caso, los Ready-mades no se agupan según la clase de objetos ni por sus afinidades materiales, formales o estilísticas inexistentes, pues, más bien, se afirman cual acontecimientos singularizados en deuda con un nominalismo literal.

Aunque a menudo se han esgrimido los Ready-mades como la manifestación por antonomasia del anti-arte o de lo artístico ${ }^{10}$, más bien creo que trasgreden las concepciones antiguas o modernas sobre el arte, en particular las de la obra y la producción. Sin embargo, las negaciones en ellas entreveradas por las convenciones no son sino la premisa ineludible para renegociar otras. Precisamente, aquéllas que vienen legitimando una "expansión" (epanouissement) del arte en cuanto despliegue y culminación de posibilidades hasta entonces nunca atisbadas en las energías, habitualmente desapercibidas y desperdiciadas, de lo infraleve (Notas, n. ${ }^{\circ} 1-46,53,137,153$ ).

Una expansión o extensión del arte que, a medida que se deja seducir por las "caricias infraleves", es cierto que se contrae en su comprehensión, pero, también, que parece progresar sin límites ni demarcaciones; propagarse con frecuencia a través de unas energías aleatorias y huidizas que impregnan por igual al acto creador como a las obras mismas. Unas obras que, en cuanto sedimentaciones materiales, aparecen un tanto desvanecidas, presas de una fragilidad quebradiza y, como sucedía ya en el Ready-made malhereux, proclives

9 Cfr. Hegel: Lecciones de estética, Madrid, Akal, 1989, págs. 122, 126, 608.

10 Cfr. N. MEYER: "La irrupción del anti-arte", en G. BATTCOCK, La idea como arte, loc. cit. págs. 93, 101; O. PAZ: Apariencia desnuda, Madrid, Alianza Forma, 1998, pág. 31. 
a la disolución o la posterior desmaterialización. Aun así, ante la tesitura de pronunciarme sobre la categoría más pertinente para esta revocación o distensión irónica de las convenciones artísticas en esta expansión de lo infraleve, me inclinaría por la que comprimiera mis sensaciones de vaciamiento, despojamiento o minoración del arte. Presumo que unas sensaciones similares cosechaba Adorno en ciertas experiencias artísticas modernas cuando nos habla de una "des-artización del arte» (Entkunstung der Kunst) ${ }^{11}$, que parece desertizar lo que solía entenderse por arte en aras de la hegemonía de la experiencia estética.

En este deslizamiento la transfiguración de los objetos en obras de arte infraleves apenas deja rastros materiales ni casi afecta a las cualidades perceptibles si no son tamizados a través de los efectos provocados por las alteraciones de su punto de vista. En realidad, la transfiguración no acontece tanto en el polo tradicional o moderno de la producción artística cuanto en el de la experiencia estética con los objetos, es decir, en el ámbito de una estética de la recepción, y, por muchas razones, podría ser considerado como un arte estético en el sentido estricto kantiano. Claro que una interpretación como ésta podría entrar en contradicción con otro testimonio tardío de Duchamp: "Cuando descubrí los Ready-mades pensé en desalentar a la estética. En el neodada han tomado mis Ready-mades y encontrado belleza estética en ellos. Les lancé a sus caras el Portabotellas y el urinario como un desafío y ahora los admiran por la belleza estéticai) ${ }^{12}$.

Una vez más, lanza los dardos del desafío en el contexto artístico radicalizado de los años sesenta contra la categoría clásica de la belleza. No obstante, en analogía con la "desublimación" coetánea de $\mathrm{H}$. Marcuse y en sintonía con la empiria artística vinculada a la "estética de lo feo" (K. Rosenkranz) y a "las artes que ya no son bellas", considero más acorde con la operación transfiguradora la interpretación de tal desafio como una «des-estetización de lo estético»

11 Th. W. Adorno: Ästhetische Theorie, Francfort/M., Suhrkamp, 1974, 2.a ed., págs. 32, $33,94,123,183,271$, etc. Este neologismo, tan inaceptable en alemán como en castellano, ha sido traducido en su Teoria estética, Madrid, Taurus, 1980, págs. 30, 31, 83, 110, 162, 240, etc., por "pérdida de la esencia artística", "vaciamiento artístico", "disolución del arte", "degeneración del arte", pero en complicidad con mi compañero, el profesor José María Ripalda, prefiero el término "desartización".

12 Citado por H. Richter: Kunst und Antikunst, Colonia, Du Mont Schauberg, 1962, pág. 212. 
(Entästhetisierung des Ästhetischen) ${ }^{13}$. Esto es, desde un nuevo despojamiento promovido por un desbordamiento de lo bello, categoría hegemónica hasta entonces, que reducía la experiencia artística a un arte bello.

Desde la óptica de la experiencia estética, los Ready-mades desbordan igualmente las fronteras aristocráticas de lo estético absorbido por lo bello, convirtiendo la «desestetización de lo estético» en el material de su arte minorado. $\mathrm{O}$, tal vez, expresándolo en otros términos, si, por un lado, promueven la "desestetización de lo estéticon, restringido éste a lo bello clásico, por otro, estimulan una "estetización de lo no estético", a saber, de las categorías modernas ligadas al desbordamiento de lo bello. El Ready-made solamente sería, por tanto, antiestético si mantenemos el equívoco de la estética clásico-idealista, que recluye lo estético en las normas y convenciones de lo bello, pero no, si lo abrimos a una estética de su desbordamiento. En esta segunda suposición la minoración de la artisticidad en el arte tiene como correlato una estetización de lo no artístico. ¡Un corolario vigente hasta el presente!

\section{La indiferencia visual en la elección y la presentación}

Si la teoría institucional se limita a actuar como telón de fondo, el punto de partida es la teoría apropiacionista del arte. «EL lo ELIGIO. Cogió un artículo ordinario de la vida" $y$, a pesar del vaciamiento o pérdida de sustancia artística frente a las convenciones, lo promovió como candidato a ser transfigurado en una obra de arte. Pero si la elección es el primer peldaño hacia ese desenlace, nada se ha dicho todavía de los criterios que la presiden. $Y$, una vez más, Duchamp nos provoca tardiamente con una de sus acostumbradas paradojas: "La elección de estos Ready-mades nunca me vino dictada por ningún deleite estético. Esta elección se basaba en una reacción de indiferencia visual, adecuada simultáneamente a una ausencia total de buen o mal gusto.... ${ }^{14}$.

Si concediésemos un crédito literal a este testimonio, sería preciso defenderse del Look del objeto, pues la dificultad para elegir estriba en que, al cabo

13 Cfr. P. Gorsen: Das Prinzip Obszön, Reinbeck bei Hamburg, Rowohlt TB, 1969, págs. 25, 37-8, 99, 109-110 o en Das Bild Pigmalions. Kunstsoziologische Essays, ibid. 1969, págs. 18$19,105-106$.

14 M. Duchamp, "A propósito del Ready-made", en Duchamp du Signe, loc. cit. pág. 164. Cfr. P. Cabanne, loc. cit. pág. 72. 
del tiempo, «uno acaba apreciándolo o detestándolo». En ambos desenlaces se caería en el hábito y la costumbre, entendida como una repetición de una cosa a ser aceptada o rechazada por una sociedad o individuo. Ahora bien, esta costumbre es la que, precisamente, es identificada por Duchamp con la categoría clásica del gusto satisfecho. ¡Bueno o malo, poco importa! Por eso, lo único que nos permite sortear este gusto, individual o colectivo, es el cultivar esa especie de indiferencia visual, de anestesia. La elección en cuanto actitud se reclamaría así a una Anestética, a una cierta insensibilidad, que no nos compromete de un modo subjetivo ni interesado.

Pero en el contexto duchampiano, ¿qué implica en realidad semejante indiferencia? Atizando su peculiar idea de la contradicción, en sus Notas había invocado una sorprendente "belleza de la indiferencia" (n. ${ }^{\circ} 68$ y 77). Esta, aunque en una primera instancia atañe a la que destilan las técnicas mecánicas en su "pintura de precisión", las cuales, al borrar los vestigios de la expresión y la interioridad del artista, no sobreentienden gusto ni preferencia algunos y son estimuladas por una inteligencia fría, se liga también con los resortes que despiertan los Ready-mades en cuanto liberación de toda realización humana, como deshumanización. De una manera un tanto paradójica, la indiferencia visual se torna una figura estética que se despliega en una doble dirección.

En efecto, la anestesia y la neutralidad en la elección de lo "ya hecho" objetan incluso la responsabilidad como si no se supiera bien si el autor elige el objeto o éste le elige a él; como si se tratase de una decisión inconsciente, sin ataduras, y se supeditase a una libertad de la indiferencia, cuya fórmula parece hallar en «el libre albedrío/Asno de Buridán» (Notas, n. 101 y 152); del asno de aquél filósofo nominalista que, como su amo, se mostraba indeciso en cual de los dos cubos llenos de cebada debía comer. Una indiferencia que, exenta de trascendencia y angustia, recuerda la actitud estética de $S$. Kierkegaard, en la que nada se resulve o todo pudiera ser de otro modo: $o$ bien o bien, desembocando así en la relatividad. Sólo que, una vez elegido el objeto, se promueve su transfiguración.

En segundo lugar, la indiferencia visual afecta también al objeto elegido. Tanto al desinterés respecto a las finalidades habituales —una indiferencia sobre la que había reparado Hegel en la naturaleza muerta ${ }^{15}$ - cuanto a la

15 HeGEL: Vorlesungen über Ästhetik, Francfort/M., Suhrkamp, B. I. 1970, pág. 214 (Lecciones de estética, loc. cit. pág. 121). 
insensibilidad hacia cualquier distinción y la devaluación gnoseológica de su significado habitual, que acaban por invertir los residuos reconocibles en relaciones. $\mathrm{O}$ mejor dicho: la inexistencia de relaciones estables provoca un estallido incontrolable de las relaciones, activa una apertura imprevisible hacia lo "Posible" en los predios de lo infraleve, a «lo Posible sometido incluso a lógicas de baja estofa/o consecuencia alegórica/de una voluntad arbitraria" (Notas, n. ${ }^{\circ} 1$ y 83). Bajo este diafragma, Duchamp sintonizará con la indiferencia óptica como figura estética central en el dadaismo, sobre todo en el berlinés, pues, diría R. Huelsenbeck, "como dadá es la falta de relación con todas las cosas y tiene por consiguiente, la capacidad de establecer relaciones con todas las cosas" ${ }^{16}$.

Tras elegir el urinario, proseguía el editorial anónimo, el sr. Mutt «Lo colocó de tal modo que su significado útil (useful) desapareció bajo el nuevo título y punto de vista: creó un nuevo pensamiento para aquel objeton. Ignoro si J. Kosuth había leído este comentario, pero, desde luego, concede a su autor el honor de haber sido el primero en plantear de un modo originario a través de los ready-mades la naturaleza de la obra artística, su deslizamiento desde una cuestión de morfología a una función, de la apariencia a la concepción: "todo arte (después de Duchamp) es conceptual (en su naturaleza), porque el arte sólo existe conceptualmente... Y lo que es cierto de la obra de Duchamp también puede aplicarse a casi todo el arte posterior a él»" ${ }^{17}$. El Ready-made se actualizaba así como excusa para una nueva tentativa universalista de definir el arte.

Esta deriva tan contundente no se sustraía al contexto artístico en el que se producía, cuyo telón de fondo era la hegemonía de lo que, desde entonces, es vituperado como arte formalista y como crítica o estética del mismo signo $(\mathrm{Cl}$. Greenberg y las teorías de la "forma significante" o incluso de la "presentacionalm), pero al mismo tiempo los trasciende. En realidad, esa crítica al formalismo, seguramente atinada, se rebelaba una coartada coyuntural para legitimar otra concepción del arte bajo las exigencias del neopositivismo a partir de unas proposiciones analíticas que, ahondando de un modo discutible en la fosa epistemológica entre la intuición sensible o percepción del mundo y el concepto,

16 R. HuelsenbeCK: Almanaque Dadá, Madrid, Tecnos, 1992, pág. 4; Cfr. mi prólogo: "El punto de indiferencia y la percepción de todas las relaciones", págs. IX-XVI, así como en Contaminaciones figurativas, Madrid Alianza Forma, 1986, pág. 140 ss.

17 J. KosuTH: Arte y Filosofia, loc. cit. págs. 66 y 67. 
separaba de una manera irreconciliable la estética y el arte. Claro que, paradójicamente, su noción de estética había quedado prendida en la crítica más banal a categorías clásicas como la del gusto o la ecuación entre la belleza y el arte, en las que la había dejado el proceso a la estética especulativa abierto por el positivismo lógico ${ }^{18}$, así como en una interesada reducción de la diferencia estética a la pureza y lo visual, que parecía destilar el formalismo de la abstracción pictórica coetánea, o a una coincidencia supuesta entre la pureza estética $y$ el arte con el formalismo criticado.

Ciertamente a Duchamp, aunque fascinado por los fenómenos de la visión le irritaba lo simplemente retiniano, como el color, las pequeñas sensaciones a lo Cézanne y otros placeres solitarios de la masturbación olfatoria a la que invitaba el olor a aguarrás. Sin embargo, al igual que le ocurría con los problemas técnicos, abogaba por saber utilizar la retina, como después se trasluciría en sus obras inspiradas en la "óptica de precisión". Tampoco parece gratuito que apelara a una "lógica de la apariencia" o a "aparición de una apariencia" (Notas, n. $67,77,250)$, es decir, al acontecimiento de una manifestación visible de un étant donné, en el que se encuentra también el Ready-made. ¿No nos ha alertado Adorno de que el centro de la estética es "la salvación de la apariencia»? ${ }^{19}$. No obstante, la gran cuestión sigue siendo como detectar la diferencia infrale$v e$, aunque presumo que ésta no se dilucida únicamente, como piensa Kosuth y de un modo más ambiguo A. Danto, en un solipsismo epistemológico ni conceptual o filosófico, sino también en el mismo acto de su ostensión.

¿Son gratuitos, por ejemplo, la colocación y el modo de llevarla a cabo? La colocación atañe al lugar que ocupa ahora el objeto. No es el habitual que tenía en la vida cotidiana: el escaparate de los sanitarios o el servicio público, sino el espacio expositivo de las obras de arte. Situado en él, el objeto elegido ya no se confunde con los restantes de la serie. Pero, a su vez, lo coloca de un modo determinado. En las sucesivas exposiciones el urinario aparece sobre un pedestal, sujeto a la pared, colgado en el techo, es decir, enajenado en sus funciones de uso o en las contextuales de la organización utilitaria del espacio; asimismo se ha alterado su posición mediante un giro de $90 \%$ que invierte el arriba y el

18 Cfr. Ogden, C. K., Richards, I. N. y WoOd, J.: The Foundations of Aesthetics, Nueva York, International Publishers, 1922; OGDEN y RicharDs: El significado del significado (1923), Buenos Aires, Paidós, 1964, págs. 124 ss., y 152 ss.

19 Th. W. AdORnO: Teoría estética, loc. cit. pág. 164. 
abajo, inutilizándolo, y teniendo como telón de fondo en la primera versión una pintura de M. Hartley, simétrica y similar en sus formas curvas al objeto elegido.

El modo de su colocación es una presentación, una exhibitio, con ostentación que lo segrega de la serie, un display que neutraliza la lógica de su distribución comercial. La colocación es la acción que consagra a la elección y a la decisión implícita en aquel enunciado no menos ostensivo: Esto es una Fuente, es decir, candidata a ser apreciada como una obra artística cuando sabemos que es un urinario. Pero el mero ser mostrado aquí y ahora este urinario y no otro, de una manera y posición alteradas, sin comparación con otras muestras de su clase, marca una primera diferencia, por infraleve que sea, con los que quedaron en el escaparate de la tienda, abandonados en el almacén o instalados en el servicio público. Neutralizado en su función o en su uso, a dejado de ser expresión de su clase objetual. El Ready-made, por tanto, no se identifica con una obra hecha, sino con un acontecimiento, con un devenir muy sutil de lo infraleve, que abandona la lógica acostumbrada de la representación en aras de la presentación. Convengo, pues, con Lyotard en que «la frase estética es por excelencia la frase de la facultad de presentación»" ${ }^{20}$.

El colocar de tal modo el objeto equivale a sacarlo de su campo habitual. Sobreviene así una descontextualización espacial que parece modificar el estatuto antológico que se insinúa en su título: Fuente. El colocarlo es ponerlo en una situación de imprevisible desenlace, cuyo primer efecto perceptible es su aislamiento. Pero, además, la Fuente es colocada sobre un pedestal al nivel del ojo del espectador iluminada desde arriba, aislada de una manera un tanto dramática, mientras la Rueda de bicicleta inserta en su horquilla se erige sobre un taburete que actúa también a modo de pedestal. A través de estos u otros "modos» los objetos surten efectos perceptibles que se desprenden de un contexto inédito. ¿ No tendrán algo que ver con ciertas cualidades sensibles, estéticas? ¿Es casual que la Fuente fuera dada a conocer a través de una fotografía, un medio que no hace, sino que elige a sus motivos?

Incluso, en los ready-mades "suspendidos», como la Percha de sombreros, sus sombras proyectadas sobre el espacio circundante evocan, como muestra una fotografía de época, figuras de la levedad en el vacío, mientras la Escultura de

20 LyOtaRd, J. F.: La diferencia, Barcelona, Gedisa, 1999, pág. 193. 
viaje — unas tiras de goma cortadas de un gorro de baño- podían colgarse de diferentes modos y configurar aleatoriamente "antiformas". Las sombras, las formas aleatorias o las "pajitas como quien/dice" (Notas, n. ${ }^{\circ} 167$ ) de una reunión de ready-mades fotografiados, surten efectos estéticos infraleves, pequeñas energías que brotan de los modos y procedimientos de colocarlos. No menos acusados son los efectos de la dislocación respecto a lo habitual y del aislamiento: la sorpresa, el shock, la provocación y, sobre todo, el extrañamiento espacial, los cuales parecen sedimentar como categorías energéticas de una nueva sensibilidad transfigurada hacia los objetos.

Las desviaciones de la finalidad o la realización de una intuición kantiana y hegeliana

Sin embargo, el efecto más decisivo de colocar de tal modo el objeto se consuma cuando el significado útil (useful) desaparece bajo el nuevo título: Fuente, y punto de vista, creando un "nuevo pensamiento" (new thought) para el objeto. Si hasta ahora la elección y la presentación sacaban a la luz cuan problemáticas se vuelven las nociones de objeto cotidiano y de la obra artística, la desaparición de su significado útil propicia nuevos desplazamientos, así como tensiones inéditas entre el polo fisico y mental que ya no abandonan a la experiencia artística hasta nuestros días. A los efectos derivados de la presentación y la dislocación espacial se suman ahora los de un extrañamiento semántico (la conocida Ostranenie de la Escuela Formalista Rusa) que estimula la alteración de funciones en atención al nuevo punto de vista o, como gustaban de decir sus amigos, a un nuevo enfoque o aproximación (new approach) al objeto.

Me parece muy sugerente este vínculo entre la desaparición del significado útil y el nuevo punto de vista. Duchamp no lo especifica en su momento, pero sí su amigo y defensor Walter Arensberg con motivo de la Fuente. "ha sido revelada una forma bonita, liberada de todo propósito funcional: por tanto, una persona ha hecho con claridad una contribución estéticas, aunque posteriormente, a propósito del Portabotellas Duchamp matizará la misma desviación al despojarlo de su coseidad: «aquel funcionalismo ya estaba obliterado por el hecho de que lo saqué de la tierra y lo acompañé al planeta de la estética ${ }^{21}$.

21 Citado por A. Camfield, M. Duchamp Fountain, loc. cit. pág. 25; M. Duchamp, "entrevista de 1953", en M. Duchamp, MOMA, 1973, págs. 275-76. 
¿No era precisamente esa falta de utilidad o propósito una de las posibilidades de lo estético que intuyera Kant? ¿Por qué no alinear a los Ready-mades, en cuanto pioneros del «arte objetual», como una de sus plasmaciones?: «Un juicio de gusto, en lo que se refiere a un objeto de fin determinado, sería puro sólo en cuanto el que juzga no tuviera concepto alguno de su fin o biciera en su juicio abstracción de éb, 22 .

Por este procedimiento, al neutralizar hasta inutilizar la función o el uso, las finalidades objetivas externas del urinario o de cualquier otro objeto útil de una serie industrial, se produce una analogía con lo que acontece en la percepción cotidiana tras el estallido de los referenciales en la quiebra de la representación. Una analogía que cristaliza a una desviación estética que recupera las apariencias, la concordancia de lo diverso en lo uno que no da a conocer finalidad ni uso algunos. Desde esta desviación creo que vale la pena seńalar las opciones insinuadas por Kant y sorprendentemente seguidas por Duchamp como posibles contribuciones estéticas.

No obstante, antes que nada, tal vez sea oportuno recordar que, desde la óptica de un objeto que posee un "fin determinadon, Duchamp era receptivo a la belleza adherente destilada por las finalidades objetivas. No en vano, estimaba a los objetos de la fontanería y a los puentes como las obras más grandes que había hecho América. Algo que no parece responder a una ocurrencia provocativa del francés, sino a una opinión extendida entre los vendedores de sanitarios al ofertar sus mercancías. Dos ańos antes la Trenton Potteries Co. señalaba: «alguien ha dicho que, hasta este momento, la gran contribución de América al arte es el cuarto de baño americano blanco y puro. Ciertamente, una de las principales contribuciones de América a la salud y el confort es su cerámica sanitaria» ${ }^{23}$.

En alguna otra ocasión Duchamp comentaba que disfrutaba de la Rueda de la bicicleta en su estudio como cuando se contemplan las llamas - nuevo motivo «infraleve" - en una chimenea, mientras que en otra asentiría ante la aseveración de su compañero de estudio, J. Crotty, de que la Pala quitanieves era el objeto más bello que había visto. Fascinación hacia los objetos del mundo técnico y de la aviación que compartía con otros muchos miembros de

22 KanT: Crítica del juicio, Madrid, Col. Austral, Espasa Calpe, 1977 y otras, $\$ 16$, pág. 131.

23 Tomado de Sanitary Pottery, n.o 7 (mayo 1915), pág. 3: citado en HigH \& Low: Modern Art / Popular Culture. Nueva York, MOMA, pág. 277. 
las vanguardias dadaístas, constructivistas soviéticas o del Purismo francés. Eran los momentos en los que, más allá de lo utilitario, se redescubría su vida mágica y sus ligazones esotéricas con la vida o incluso la estética de la máquina.

Pero no menos sintomática considero la sintonía con los juicios en los que quien juzga "no tuviere concepto alguno de su fin», ya que atañe a la desaparición del significado y el cambio de funciones en numerosos objetos u obras del pasado: «las cucharas de madera africanas, conversa Duchamp, no eran absolutamente nada en el momento en que las hicieron, únicamente eran funcionales; después se convirtieron en cosas hermosas, en "obras de arte" o somos nosotros quienes hemos dado el nombre de "arte" a las cosas religiosas; lo hemos hecho pensando en nosotros, en nuestra propia satisfacción» ${ }^{24}$.

Frente a estas posibilidades vislumbradas por Duchamp, Kosuth sostiene que "cualquier cosa física puede convertirse en objet d'art, es decir, puede ser considerada de buen gusto, estéticamente agradable. Pero esto no guarda la menor relación con la aplicación del mismo objeto a un contexto artístico, es decir, con su funcionamiento en un contexto artísticom ${ }^{25}$, pues no tiene en cuenta las intenciones del propio artista. Presumo que Duchamp había rebatido de antemano esta posición y, en menor medida, la de A. Danto. Ambos, al pasar por alto las cualidades visuales y afirmar que la estética no tiene conceptualmente la menor importancia para el arte, reducen la obra a una tautología y renuncian a lo ostensivo, a toda presentación y exhibición de las apariencias: «la presentación de los objetos dentro del contexto del arte (...) no es merecedora de mayores consideraciones estéticas que las de cualquier otro objeto del mundo" ${ }^{26}$, sustituyéndola por una presentación de las intenciones del artista. Ahora bien, ¿qué sucederá cuando, como es lo más habitual, éstos no se conocen? El radio de acción de semejante hipótesis es muy limitado, incluso para las experiencias artísticas coetáneas y, desde luego, Duchamp siempre distinguió, sobre todo en El proceso creativo, entre las intenciones del artista y las realizaciones concretas.

Desde esta consideración, además, los objetos religiosos, útiles o comunicativos, fueron también hechos, aunque fuesen sin intenciones artísticas y en ellos tampoco nos es posible eliminar sus configuraciones formales. Lo que es

24 P. Cabanne: Conversaciones con M. Duchamp, loc. cit. págs. 110 y 163.

25 J. KosuTH: Arte y Filosofia, loc. cit. pág. 67.

26 J. KosUTH: ibid. pág. 64. 
evidente, como se aprecia en las artes primitivas o incluso en los objetos antiguos, es que la mirada moderna ha introducido cambios de funciones una vez que aquéllos han perdido o neutralizado las originarias. Sin que haya sido necesaria intervención alguna y, menos, una puesta al día de sus intenciones insondables, se han transfigurado en obras de arte. La capacidad diferenciadora de la conciencia artística moderna, ya sea a cargo del artista, como en el Primitivismo moderno o del espectador, impulsa esta transfiguración, dejando fuera de juego todo intencionalismo, irrecuperable por otro lado en la mayoría de las situaciones. De otra manera, desaparecerían capítulos enteros de lo que hoy en día incluímos en la historia o en los museos de arte. Es bien sabido cómo los chinos y japoneses seleccionaban piedras que, colocadas en los jardines, se transformaban en elementos artísticos. $\mathrm{Y}$ algo similar acontece con los objetos técnicos modernos, como también intuía el Purismo francés ${ }^{27}$, y con las imágenes fotográficas o publicitarias, ya que, cuando han perdido sus funciones utilitarias, de reportaje o comunicativas, devienen obras de arte "infraleves" ajenas a las intenciones de sus hacedores. Asomaría así una estética del acontecimiento que se desliza en el transcurso de la temporalidad de los objetos y las modificaciones de funciones.

No obstante, si la anterior opción mira ante todo de un modo retrospectivo hacia el pasado, la que postula: "cuando se hiciere en su juicio abstracción del firm...., en cualquiera de sus acepciones, se actualiza en el presente y se proyecta hacia el futuro. Esta abstracción es la que cristaliza cuando desaparece la función útil originaria bajo el "nuevo punto de vista». La devaluación gnoseológica de los significados y el vaciado semántico promueven una inversión de los residuos objetuales reconocibles, aunque flotantes en el recuerdo, en unas relaciones de estímulos perceptivos y mentales. He sugerido ya que en la elección y en la presentación operan dispositivos artísticos que surten efectos estéticos, pero ahora es oportuno resaltar que la presentación no se limita a una ostensión estática de las apariencias, sino que, más bien, se inscribe en un devenir del objeto, en un acontecimiento, y actúa a modo de puente tendido entre la intuición sensible mediante la cual el objeto nos es dado y una "concepción a matizar. Como secuela de semejante puenteo la consideración estética de los Ready-mades no se recluye en la percepción de las apariencias, sino que se

27 Cfr. F. LÉGER: “L'Esthétique de la Machine», Bulletin de l'Effort Moderne, 1, n. $1-2$ (1924), pág. 5. 
expande hacia un nuevo punto de vista capaz de crear un «nuevo pensamiento" para ese objeto.

Probablemente, este "nuevo pensamiento" da excusa a Kosuth y Danto para interpretar el Ready-made como el acontecimiento originario, auroral, después del cual todo arte es "conceptual", esto es, sólo existe conceptual o filosóficamente. Creo que se trata de una deducción en la que el «nuevo concepto» suplanta al "nuevo pensamiento", ignorando así la conocida distinción entre un concepto bajo el cual un objeto es subsumido o la asignación del concepto a la intuición sensible correspondiente del objeto, y el pensamiento, en cuyo ámbito la asignación sólo se produce como simple espontaneidad de la unión de la diversidad en una intuición meramente posible, según los diferentes modos ${ }^{28}$.

Incluso, por deferencia a la sintonía de A. Danto con la estética de Hegel, me permito recordar, trazando una analogía, que cuando este autor incorpora la realidad dada, tan prosaica y vulgar para su época como la del urinario, como material artístico, expande las naturalezas muertas hacia una "apariencia producida por el espíritu" (durch den Geist produzierte Schein) como milagro de una "idealidad". Una idealidad en la que, precisamente, "el arte es el punto medio entre el ser-ahí meramente objetivo y la representación (Vorstellung) meramente interna» ${ }^{29}$.

Ahora bien, al colocar el Ready-made en una nueva situación puede suceder al igual que en aquellas "naturalezas muertas», que nos «quedemos sólo con la relación que, según nuestras necesidades, placeres, nuestra distinta formación y distintos fines, tenemos con tales objetos, es decir, los aprehendamos sólo según su conformidad o fin externo (aussere Zweckmässigkeit), pero la vitalidad del objeto es anulada». En esta suposición, la "cito» fracasa por completo. Pero también puede ocurrir lo contrario, ya que la idealidad ilusionante del arte, por infraleve que en nuestro caso fuere, «eleva al mismo tiempo a los objetos, de otro modo carentes de valor, a los que... fija para sí y convierte en fin, $y$ dirige nuestra atención a lo que de otro modo dejaríamos pasar desapercibido» ${ }^{30}$. ¿De un plumazo el intencionalismo ha sido desplazado por la intencionalidad, el psicologismo por la fenomenología!

28 I. KANT: Critica de la razón pura, Madrid, Clásicos Alfaguara, 1998, 5.a ed. B 146, pág. 162-3; B 304, pág. 266; B 428, pág. 379.

29 HEGEL: Vorlesungen über Ästhetik, I, loc. cit. 215. (Lecciones de estética, loc. cit. pág. 122).

30 HEGEL: Vorlesungen über Ästhetik, III, pág. 63 y I págs. 215-216. (Lecciones de estética, loc. cit. pág. 608 y 122). 
Sería apasionante el desvelar cómo en la reflexión hegeliana se filtra la desviación kantiana de las finalidades. No obstante, en esta ocasión, me importa resaltar que mientras en la primera suposición el objeto es consumido en virtud de su finalidad objetiva externa, de su conexión con el mundo real y las necesidades prácticas, integrado en un conjunto de funcionalidades y en la teoría de los valores, en la segunda, desprovisto de su función o abstraído de sus usos, recobra en sí mismo una vitalidad, incluso un aura, que nos invitan a reparar en aspectos hasta entonces inesenciales, en la abstracción formal que destilan las apariencias de la mercancía. Precisamente, esta vitalidad virtualmente recuperada, indiferente a los valores de uso y de cambio, impulsa los nuevos puntos de vista a modos diferentes, la apertura a las nuevas avenidas, aquel extrañamiento que propicia la eclosión potencial de las relaciones en todas las direcciones. La desviación idealista de las finalidades se vería así reforzada por la abstracción un tanto fetichizada del objeto como mercancía sobre la que nos alertarán tanto Marx como Baudelaire.

Los desafios de estas desviaciones nos retan a una «cita» más prolongada, incluso diferida, con el objeto, pero a su vez suscitan la sospecha de si aquél nuevo pensamiento, en el que desemboca la aventura transfiguradora, no será la culminación de una puesta en órbita de una idea estética en la acepción kantiana. ¿No sería posible abordar la desaparición del significado útil desde esta óptica?

Tal vez, retomando la connivencia de la "desartización" con la experiencia estética, me da la impresión de que en los Ready-mades se mantiene todavía despierto y activo el Espíritu o principio vivificante del que nos habla Kant, esa facultad de exposición de ideas estéticas. La transfiguración de los objetos en obras «infraleves" de arte no sólo se actualiza a través de la insinuada facultad de presentación, de ostensión, sino de esta facultad de exposición o, mejor, de representación (Darstellung, aunque los objetos, por no tener función representativa, se representan únicamente a sí mismos) de ideas estéticas, entendida como «representación (Vorstellung) de la imaginación que provoca a pensar mucho, sin que, sin embargo, pueda serle adecuado pensamiento alguno, es decir, concepto alguno" o "empujada a un concepto dado y unida con tal diversidad de representaciones parciales (Teilvostellungen) en el uso libre de la misma que no se puede para ella encontrar una expresión que indique determinado concepto» ${ }^{31}$.

31 KANT: Critica del juicio, $\$ 49$, págs. 220 y 223 . 
Esta inadecuación y diversidad de representaciones parciales se asocian en los Ready-mades, más que con un nuevo pensamiento en singular, con nuevos pensamientos que fluyen de distintas fuentes. No en vano, en la Fuente los amigos de Duchamp ponían en juego tanto las cualidades formales: la forma, las curvas, el color, la epidermis o la simplicidad, relacionadas con un Buda encantador o con las piernas de las bañistas de Cézanne, como las sugestiones formales y sexuales cercanas a la Princesa $X$ de su amigo Brancusi, si es que no, desde el punto de vista antropomórfico, su parecido con una Madonna del Cuarto de Baño o con las reminiscencias atávicas de los fetiches adheridos a la mercancía, etc. La emancipación y liberación del objeto respecto a las ataduras habituales recuperan una vitalidad cuyos efectos estéticos son deudores de las experiencias visibles y de las apariencias producidas por el espíritu en permanente puenteo a través de unas estrategias entre las que destacan las alegóricas ${ }^{32}$.

Tanto la desviación de fines como la recuperación de la vitalidad del objeto guardan una analogía estrecha con la desviación de la percepción cotidiana a través del estallido de los referenciales y la concentración en el significante artístico que se aprecia en la obra moderna. Un estallido similar resuena ahora en los materiales objetuales a través de los dispositivos o estrategias artísticas «infraleves" que activan virtualmente cualquier relación, desbordando por ello toda interpretación. En otras palabras, si bien los Ready-mades suscitan, como presumía Duchamp, «interesantes» interpretaciones, ninguna de ellas es la última ni definitiva. Queda una y otra vez aplazada, diferida, en perpetua fuga sin fin. Ni siquiera él mismo se ponía de acuerdo consigo mismo sobre si éstos objetos inespecíficos eran arte, antiarte o algo indiferente que se ubicara en una tierra de nadie entre ambos.

Pero, posiblemente, tanto aquella desviación como este diferimiento incesante son los síntomas más palpables de que en ellos anida aún la diferencia estética. Y, sin embargo, al constatar esta diferencia, por infraleve que sea respecto a los objetos que han permanecido en la vida ordinaria, en los Ready-mades, en cuanto presentación y exposición de ideas estéticas (tanto en el sentido de Darstellung como de Vorstellung), abstraen o ponen entre paréntesis, pero no eliminan, los pensamientos o contenidos extraestéticos. Por eso, los ataques a la "distinción estética» kantiana, como los de Gadamer ${ }^{33}$, únicamente son

32 Cfr. José Luis BREA: Nuevas estrategias alegóricas, loc. cit., sobre todo pág. 47 ss.

33 Cfr. H. G. GADAMER: Verdad y método, Salamanca, Sígueme, 1977, págs. 125-126. 
eficaces si, previamente se la reduce a la que destila la obra de arte pura en la abstracción moderna. La diferencia estética, en mi opinión, no elimina los momentos extraestéticos, pero sí los subordina a unapredominancia que organiza en un uso libre las representaciones parciales tamizándolas en una autounificación que las conserva transfigurándolas y alejándolas de toda comprensión automática que se subsuma en el concepto.

\section{Conclusión}

Si he tomado como motivo para repensar la diferencia estética a la Fuente es porque, al igual que Malevich alcanza el grado cero de la pintura o el Minimalismo el de la escultura, Duchamp reduce a su grado cero la transfiguración artística del objeto. Probablemente por ello, la Fuente, muestra ostensiva de unos Ready-mades genéricos e inespecíficos, ha quedado incorporada a la historia del arte más reciente como uno de sus hitos más paradigmáticos. Y eso después de que, vetada como obra artística, no queria ser arte. Incluso, la idea estética que anida en ella: la transfiguración artística de los objetos de la vida ordinaria ha fructificado cual semilla cuya energía potencial sedimenta en sucesivas objetivaciones o distribuciones nómadas que se reclaman a esa suerte de principio inmanente de autounificación en que se ha convertido la modalidad del arte objetual durante casi un siglo.

La Fuente parece por tanto brotar como una manifestación auroral de aquella intuición kantiana que desborda los cauces de cualquier previsión y está forzando un replanteamiento en el debate estético contemporáneo. Asimismo, a partir de ella sería posible trazar una genealogía del arte moderno, complementaria a la de otras vetas. Discurriría desde el dadaismo y el surrealismo objetuales hasta los neodadaismos varios, y del "pop art», vía el conceptualismo, hasta los apropiacionismos y el arte contextual más próximos.

Por supuesto, pertenece a la historia y la critica de arte la tarea de explorar los procedimientos o estrategias artísticas usufructuadas en las transfiguraciones posteriores y actuales, mientras la teoría estética se muestre receptiva a las nuevas condiciones y modificaciones, tanto desde la óptica de los objetos como desde la del arte, en las que se despliegan las experiencias artísticas en los horizontes del sistema objetual y del mass-mediático. Desde estos nuevos escenarios, creo que la diferencia estética se ve forzada a mediar, desoyendo los negros presagios de su propia desaparición, en las tensiones, ciertamente radicalizadas, 
entre las tendencias del arte a la des-artización y las de la vida cotidiana a la estetización difusa. Su polaridad lanza unos desafíos que me propongo afrontar en otra ocasión, consciente de que en estos espacios de inseguridad el factum y la precariedad de la reflexión se convierten alternativamente cada uno de ellos en mediación del otro. 